\title{
Plant and Fungal Food Components with Potential Activity on the Development of Microbial Oral Diseases
}

\author{
Maria Daglia, ${ }^{1}$ Adele Papetti, ${ }^{1}$ Dora Mascherpa, ${ }^{1}$ Pietro Grisoli, ${ }^{1}$ \\ Giovanni Giusto, ${ }^{2}$ Peter Lingström, ${ }^{3}$ Jonathan Pratten, ${ }^{4}$ Caterina Signoretto, ${ }^{5}$ \\ David A. Spratt, ${ }^{4}$ Michael Wilson, ${ }^{4}$ Egija Zaura, ${ }^{6}$ and Gabriella Gazzani ${ }^{1}$ \\ ${ }^{1}$ Department of Drug Sciences, University of Pavia, Viale Taramelli 12, 27100 Pavia, Italy \\ ${ }^{2}$ DIP.TE.RIS., University of Genoa, Corso Europa 26, 16132 Genoa, Italy \\ ${ }^{3}$ Department of Cariology, Institute of Odontology, The Sahlgrenska Academy, University of Gothenburg, 40530 Götegborg, Sweden \\ ${ }^{4}$ Department of Microbial Diseases, UCL Eastman Dental Institute, 256 Gray's Inn Road, London WC1X 8LD, UK \\ ${ }^{5}$ Sezione di Microbiologia, Dipartimento di Patologia e Diagnostica, Università di Verona, Strada Le Grazie 8, 37134 Verona, Italy \\ ${ }^{6}$ Department of Preventive Dentistry, Academic Centre for Dentistry Amsterdam (ACTA), Gustav Mahlerlaan 3004, \\ 1081 LA Amsterdam, The Netherlands
}

Correspondence should be addressed to Gabriella Gazzani, gabriella.gazzani@unipv.it

Received 15 June 2011; Accepted 19 July 2011

Academic Editor: Carla Pruzzo

Copyright ( $) 2011$ Maria Daglia et al. This is an open access article distributed under the Creative Commons Attribution License, which permits unrestricted use, distribution, and reproduction in any medium, provided the original work is properly cited.

\begin{abstract}
This paper reports the content in macronutrients, free sugars, polyphenols, and inorganic ions, known to exert any positive or negative action on microbial oral disease such as caries and gingivitis, of seven food/beverages (red chicory, mushroom, raspberry, green and black tea, cranberry juice, dark beer). Tea leaves resulted the richest material in all the detected ions, anyway tea beverages resulted the richest just in fluoride. The highest content in zinc was in chicory, raspberry and mushroom. Raspberry is the richest food in strontium and boron, beer in selenium, raspberry and mushroom in copper. Beer, cranberry juice and, especially green and black tea are very rich in polyphenols, confirming these beverages as important sources of such healthy substances. The fractionation, carried out on the basis of the molecular mass (MM), of the water soluble components occurring in raspberry, chicory, and mushroom extracts (which in microbiological assays revealed the highest potential action against oral pathogens), showed that both the high and low MM fractions are active, with the low MM fractions displaying the highest potential action for all the fractionated extracts. Our findings show that more compounds that can play a different active role occur in these foods.
\end{abstract}

\section{Introduction}

During the last decades, a close relation between diet and health have been pointed out by the findings of a large number of epidemiologic investigations. Due to these findings, today, foods are no more considered just for their nutritive value, but also for their potential positive effects in preventing and protecting against serious chronic diseases with strong socioeconomic implications in Western countries such as neoplastic, cardiovascular, neurodegenerative diseases, cataracts, diabetes, metabolic syndrome, inflammatory process, and aging. As regards cancer, for example, it is estimated that its incidence could be reduced by at least $30 \%$ adequately increasing diet vegetables and fruits.
The foods producing peculiar beneficial effects on human health are generally defined as functional foods. Up to date, there is not a generally accepted definition for functional foods. The USA and UE have no legal definition of a functional food that in these countries is strictly a marketing term, even if UE recognizes for some foods specific health claims [1]. Japan is the only country that has an established regulatory framework for functional food marketing, which dates back to the 1980s. Some organizations, such as the International Food Information Council (IFIC, founded in 1991), have attempted to establish a definition. The IFIC regards them as "foods that provide a health benefit beyond basic nutrition." The Institute of Medicine's Food and Nutrition Board (IOM/FNB, founded in 1970) defined 
functional foods as "any food or food ingredient that may provide a health benefit beyond the traditional nutrients it contains." After this definition, foods, technological-treated food products, and their active components that can be used to prepare enriched and fortified foods or be assumed separately from foods as supplements may be considered as functional foods.

In its latest position paper, the American Dietetic Association (ADA, founded in 1917) defines a functional food as one that provides a "beneficial effect on health when consumed as part of a varied diet on a regular basis at effective levels." The organization classified functional foods into four groups: conventional foods, modified foods, medical foods, and foods for special dietary use, and called for more research into their potential health benefits.

Moreover, most of the researchers consider there is a clear difference between dietary supplements, or nutraceuticals, and functional foods. The former, which include vitamins, minerals, other substances with physiological effects, and botanicals, are taken in a dose form [2]. Anyway, other researchers consider that a nutraceutical is any food that giving nutriment helps to maintain health [3].

Among chronic diseases whose development can be influenced by the consumption of specific foods, also oral diseases such as caries and gingivitis, that are the most common and diffused infectious diseases in the world, should be counted. A consortium of microorganisms, among which Streptococcus mutans and Streptococcus sobrinus are considered the most influent, is involved in the development of such pathologies. It is well known that oral pathogens virulence can be strengthened or conversely inhibited by dietary factors. For a long time, the negative role of diet sucrose in inducing caries formation has been recognized. Recently, the emergence of pathogen resistance to conventional antibacterial agents and the need to develop new strategies for the control of infectious diseases made active the research about natural compounds able to act as antimicrobial agents. Such research led to the findings that compounds, able to act with different mechanisms, against the main infective responsible agents for oral diseases, occur in a lot of vegetable and fungal foods. First, the different kinds of tea in in vitro and in vivo both in animal and humans were studied for their protective action against oral pathologies above all by Japanese researchers. Tea polyphenols were shown to be able to inhibit caries development reducing $S$. mutans cell surface hydrophobicity and its capability to produce, starting from sucrose, the insoluble, bioadhesive polymer glucan that allows the dental plaque formation [48]. Then coffee and cocoa were studied. Our previous in vitro investigation pointed out since 1994 that coffee beverage possesses a wide spectrum antibacterial activity. Such activity was found to be relevant against a number of Gram-positive and Gram-negative microorganisms including Streptococcus mutans and other pathogens such as Staphylococcus aureus and Escherichia coli [9-11]. Later, it was found that also white and red wine, and barley coffee possess antimicrobial activity. Coffee components able to act against oral pathogens, in the experimental-used model system, were found to be the $\alpha$-dicarbonyl compounds formed during roasting process (green coffee did not show any antibacterial activity). Interestingly, $\alpha$-dicarbonyl compound activity resulted to be strongly enhanced in the presence of caffeine that alone showed no activity in the same system [12]. As regards wine, most of the antibacterial activity was due to the presence of the low-molecular organic acids naturally occurring in grape or formed during malolactic fermentation process [13].

These results, indicating a potential positive action of coffee and wine in protecting oral health due to the presence of compounds able to inhibit dangerous microorganism proliferation, prompted us to investigate the same beverages for more specific actions that have the capability to inhibit pathogen adhesion to and to induce pathogen detachment from hydroxyapatite (HA) beads in in vitro tests. Chlorogenic acid, trigonelline and nicotinic acid, and also highmolecular-mass melanoidin components were identified as antiadhesive compounds in coffee, whereas as regards red wine, a fraction containing anthocyanins and proanthocyanidins showed the highest activity [14]. Considering barley coffee, it was found that very high-molecular-mass brown melanoidinic components were able to remarkably inhibit $S$. mutans adhesion to and induce detachment from HA and to inhibit biofilm production $[15,16]$.

As regards cocoa, a number of papers reported anticariogenic effect of water soluble components and in particular of polyphenols [17-20].

Among the most studied foods in this field also propolis had to be cited [21]. Recently, a potential use of propolis as a cariostatic agent was reported [22].

The promising findings of research in this field prompted the UE to fund a systematic program of research about the ability of food/beverage constituents to protect against oral infectious diseases, that is, caries and gingivitis.

The first basic step in this contest was the selection of the food/beverages to be investigated. Due to the number of literature papers reporting polyphenols as antimicrobial and antiadhesive agents also able to interfere with biofilm and glycosyl-transferases production, plant and fungal edible materials were decided to be useful for our purposes. So, already studied materials such as green and black tea leaves, mushroom, and cranberry were selected for a systematic investigation as well as raspberry, red chicory, and beer never previously studied in relation to a potential action in protecting oral cavity from infection diseases.

The selected food/beverages had to be analysed to state their content of macronutrients, that is, protein, lipid, and total carbohydrates. Also free sugars, micronutrients such as inorganic ions that were found to exert any positive or negative influence on oral health, and the total polyphenol content of the selected food/beverages were evaluated. As the selected materials had to be tested in biological assays, useful solutions of their water soluble components had to be prepared (extracts) and their microbiological quality to be defined. Furthermore, the fractionation of the most active extracts (red chicory, mushroom, and raspberry) was performed on the basis of their molecular mass as a first step to isolate the active compound/s. 


\section{Materials and Methods}

2.1. Chemicals and Reagents. Concentrated sulphuric acid $(97 \%)$, sodium hydroxide $1 \mathrm{~N}$, petroleum ether $40-70^{\circ} \mathrm{C}$, mixed indicator solution (Methyl Red-Methylene Blue) were purchased from Carlo Erba Reagents (Milan, Italy).

2.2. Materials. Frozen mushrooms (shiitake, Lentinus edodes) were purchased from Bolem (Gorizia, Italy) and Asiago Food SpA (Veggiano, Italy). IGP "Rosso Tardivo of Treviso" red chicory (Cichorium intybus L., variety Silvestre (Bishoff) typology Tardivo) was purchased from Italian Consorzio Radicchio di Treviso (Treviso, Italy). Raspberries were purchased from Agrifrutta Soc. Coop. Agr. (Peveragno, Italy). Green and black tea (Camellia sinensis) dry leaves were purchased from an Italian tea importer (Berardi \& C. S.n.c., Milan, Italy). Dark beer (Guinnes draught, 4.2\% alcohol) was purchased from a local supermarket. Cranberry juice was acquired as concentrated juice from an Italian importer (Natex International trade spa, Pioltello, Italy) of Ocean Spray Cranberries Inc. (Lakesville-Middle-boro).

2.3. Extract Preparation. Aliquots of fresh red chicory $(500 \mathrm{~g})$, of frozen mushroom, and of frozen raspberries (400 g) were homogenized (for 1, 2, and $1 \mathrm{~min}$, resp.) and centrifuged (for $10 \mathrm{~min}$ at $8000 \mathrm{rpm}$ ), and the juices, after separation from solid parts, were filtered on paper filter, and then submitted to sterile ultrafiltration, with the exception of raspberry juice. Green and black tea infusions were prepared from a suspension containing $30 \mathrm{~g}$ of dry leaves in $600 \mathrm{~mL}$ of water Millipore grade; after 5 minutes of infusion, the extracts were cooled at $20^{\circ} \mathrm{C}$, filtered on paper filter, and then subjected to sterile ultrafiltration. Concentrated cranberry juice (5.6X) supplied by the importer was simply diluted before the analysis. Aliquots $(325 \mathrm{~mL})$ of Guinnes beer were submitted to elimination of $\mathrm{CO}_{2}$ [23] and dealcoholated (bath temperature: $50^{\circ} \mathrm{C}$, vacuum: 30 bar for 20 minutes).

2.4. Moisture Content Determination. Moisture was determined following the official method of analysis of AOAC International [24]. Values are means of four independent experiments.

2.5. Protein Content Determination. Kjeldahl method, the standard method of nitrogen determination, was used following the official method of analysis of AOAC International $[25,26]$. Values are means of four independent experiments.

2.6. Lipid Content Determination. The Soxhlet method, as described in the official method of analysis of AOAC International [27], was applied. Values are means of four independent experiments.

2.7. Free Sugars Determination. D-glucose, D-fructose, and sucrose contents were determined using an enzymatic assay (Boehringer Mannheim, R-Biopharm, Italia srl, Cerro Al Lambro, Italy). D-glucose concentration was determined before and after the enzymatic sucrose hydrolysis, while Dfructose was determined subsequent to the determination of D-glucose. The other sugars (arabinose, galactose, mannose, rhamnose, ribose, xilose, and maltose) were revealed by thinlayer chromatography following the method of Talukder [28]. Values are means of four independent experiments.

2.8. Mineral-Content Determination. An ICP-OES Perkin Elmer Optima 3300 DV was used for the measurements of metal ions at concentration greater than $5 \mu \mathrm{g} / \mathrm{L}$, and, for more diluted samples, inductively coupled plasma-mass spectrometer (ICP-MS) measurements were carried out on a Perkin Elmer Mod. ELAN DRC-e instrument. In both cases, the standard procedures suggested by the apparatus manufacturers have been followed. Linearity range between the intensity and concentration for each metal ion was obtained using standard solutions daily prepared from a $1.00 \mathrm{mg} / \mathrm{mL}$ stock solution. LODs were calculated as the amount of metal ion that gives a signal that is $3 \sigma$ of the mean blank signal and LOQ as the amount of metal ion which gives a signal that is $10 \sigma$ above the mean blank signal. Accuracy was checked by spikes recovery.

Fluoride ion concentration was measured by fluoride ISE on an Orion 520 potentiometer, with the standard additions method. Values are means of four independent experiments.

2.9. Total Polyphenol Content Determination. Total polyphenol contents were determined with the Folin-Ciocalteu reagent. In brief, $500 \mu \mathrm{L}$ of Folin-Ciocalteu reagent was added to $100 \mu \mathrm{L}$ of each extract, mixed, and added with $2000 \mu \mathrm{L}$ of a $15 \% \mathrm{Na}_{2} \mathrm{CO}_{3}$ solution and Millipore grade water to a $5 \mathrm{~mL}$ final volume. After mixing and waiting for $2 \mathrm{~h}$, the mixtures were read spectrophotometrically at $750 \mathrm{~nm}$. ( \pm ) Catechin was used as the phenolic standard compound [29]. Values are means of four independent experiments.

2.10. Microbiological Quality Control of Food/Beverage and Extracts [30, 31]. The microbiological quality controls were done through qualitative and quantitative analysis to determine the following indicator organisms:

(1) Total viable count (psychrophilic/mesophilic/bacteria) through plate count with Tryptone Soya Agar (Oxoid Ltd., Basingstoke, Hampshire, UK);

(2) Yeast and mould plate count with Malt Extract Agar (Oxoid Ltd., Basingstoke, Hampshire, UK) and Potato Dextrose Agar (PDA) (Oxoid Ltd., Basingstoke, Hampshire, UK);

(3) Enteric indicator bacteria through plate count: determination of Escherichia coli with Violet Red Bile Glucose Agar (Oxoid Ltd., Basingstoke, Hampshire, UK), Salmonella spp with XLD Medium (Oxoid Ltd., Basingstoke, Hampshire, UK), Streptococcus faecalis with Slanetz and Bartley Medium (Oxoid Ltd., Basingstoke, Hampshire, UK), Sulfite reducing Clostridium spores with SPS Agar (Oxoid Ltd., Basingstoke, Hampshire, UK);

(4) Environmental indicator through plate count: determination of Pseudomonas spp with Pseudomonas Agar Base (Oxford) (Oxoid Ltd., Basingstoke, Hampshire, UK); 
(5) Antrophic indicator bacteria through plate count: determination of coagulase-positive Staphylococci (Staphylococcus aureus), determination of coagulasenegative Staphylococci (Staphylococcus epidermidis) with Baird Parker Agar Base (Oxoid Ltd., Basingstoke, Hampshire, UK), and Egg Yolk Tellurite Emulsion (Oxoid Ltd., Basingstoke, Hampshire, UK);

(6) Animal indicator bacteria through plate count: determination of Listeria monocytogenes with Lysteria selective Agar Base (Oxford) (Oxoid Ltd., Basingstoke, Hampshire, UK) Lysteria selective supplement (SR 140 E) (Oxford) (Oxoid Ltd., Basingstoke, Hampshire, UK).

The possible presence of pathogen microorganisms in foods was confirmed with biochemical identification systems.

2.11. Extract Fractionation. The chicory and mushroom extracts fractionation was performed using Vivaflow 200 complete system (Vivascience) equipped with 5,000 MWCO PES membrane. The diafiltrate $(\mathrm{MM}<5,000 \mathrm{Da}-\mathrm{LMM})$ and the retentate $(\mathrm{MM}>5,000 \mathrm{Da}-\mathrm{HMM})$ fractions obtained from each extract aliquot of $250 \mathrm{~mL}$, after restoring the initial volume, were submitted to sterile ultrafiltration, freeze-dried, and tested.

Raspberry extract was fractionated into low- and highmolecular-mass fractions by dialysis. Dialysis was performed using a Spectra/Por Biotech regenerated cellulose membrane (Spectrum Europe B.V., Breda, The Netherlands) with a molecular mass cutoff (MMCO) of 3,500 Da. Aliquots $(60 \mathrm{~mL})$ of raspberry extract were fractionated by dialysis in $5600 \mathrm{~mL}$ of Millipore grade water for $24 \mathrm{~h}$ at $4^{\circ} \mathrm{C}$. The $\mathrm{pH}$ values ( $\mathrm{pH} 3.20)$ of LMM and HMM fractions, reconstituted to the initial volume $(60 \mathrm{~mL})$, were brought to $\mathrm{pH} 4.5-5.0$ (using 1.0 M NaOH) not to interfere with subsequent assays of their biological activities. Then the fractions were sterilized using ultrafiltration $0.20 \mu \mathrm{m}$ membrane and freeze-dried.

\section{Results and Discussion}

In the selected raw food/beverages (red chicory, mushroom, raspberry, green and black tea, cranberry juice, and dark beer), proteins, lipids, total carbohydrates, and sugars such as glucose, fructose, and sucrose were quantitatively determined, whereas the presence of other monomeric or dimeric sugars were just pointed out. Among mineral components, the generally considered as positively influencing oral health ions such as fluoride, zinc, strontium, molybdenum, boron, and lithium and the generally indicated as negatively acting selenium, beryllium, copper, and lead were detected. The total content of polyphenols, compounds often indicated as able to interfere with different steps in caries development process, was also determined in the seven selected raw materials.

In Table 1, the content of water, macronutrients, and ash of the selected food/beverages was reported.

Carbohydrates are the most abundant macronutrients in all the selected food/beverages. Green and black tea show values higher than $60 \%$, cranberry about $50 \%$, and all the other materials less than $15 \%$.

Carbohydrates are important as regards caries development when they are fermentable by oral pathogens that, embedded in dental plaque, can continuously produce organic acids (mainly lactic acid) able to demineralise the protective tooth-calcified tissues.

Among fermentable sugars, sucrose is considered as the most cariogenic sugar because the capability of microorganisms to rapidly metabolise sucrose producing both organic acids and extracellular bioadhesive polysaccharides is a relevant oral pathogen virulence trait.

As regards sugars, glucose, fructose, and sucrose determination was performed in all the food/beverages applying specific enzymatic methods (Table 2 ).

Black tea and beer were found not to contain any of such sugars probably because they are metabolized during fermentation process they undergo. All the other selected materials contain these sugars in very small amount (less than $1 \%$ ), with the exception of cranberry in which glucose percentage is close to $3 \%$. Thin-layer chromatographic analysis showed the presence of other monomeric and dimeric sugars as reported in Table 3.

Lipid content is very low in all the selected food/ beverages with beer showing not to contain lipids at all (Table 1).

The richest in protein materials are green and black tea leaves. Due to the treatment tea leaves undergo, their moisture content is low (about 8\%), determining the increase of the other component percentages; therefore, tea leaves protein content reaches remarkable values similar to that of animal foods or other dry plant foods such as dry legumes. All the other materials are very low in protein and very high in water content including raspberry, mushroom, and red chicory, although they are solid materials. It is known that fresh vegetables and fruits have a high content of water and a high activity water value so that their shelf life is quite short even if stored at refrigerate temperature because free water is abundant and available for microorganisms proliferation (Table 1).

So it is not surprising that red chicory and raspberry presented a marked microbial contamination (Table 4). In particular, red chicory presented the highest contamination values for total microbial counts (mesophilic, psychrophilic, and yeasts) and for specific indicators of contamination such as Enteric indicator (Escherichia coli $740 \mathrm{cfu} / \mathrm{mL}$ ) and Environmental indicator (Pseudomonas spp $1000 \mathrm{cfu} / \mathrm{mL}$ ), whereas any food showed important microbial indicators of antrophic or animal contamination such as Staphylococcus aureus, Salmonella spp, and Listeria monocytogenes.

Considering the elements (Table 5), green and black tea are very rich in fluoride $(\mathrm{F})$ ions in comparison with the other food/beverages (about $40 \mathrm{ppm}$ ). F exerts a very important action in protecting from dental caries. When dental structure is forming, $\mathrm{F}$ ions are able to replace hydroxyl group in HA giving fluoroapatite a very protective material that more than $\mathrm{HA}$ resists acid attack that determines enamel demineralisation. Protective F action continues even when tooth is formed because this anion promotes enamel 
TABLE 1: Water, macronutrients, and ash content of the selected food/beverages ( $\mathrm{g} / 100 \mathrm{~g}$ edible material).

\begin{tabular}{lccccccc}
\hline Edible material & Red chicory & Mushroom & Raspberry & Green tea & Black tea & Cranberry & Beer \\
\hline Water $^{(1)}$ & 94.00 & 89.00 & 84.50 & 7.70 & 8.00 & 49.20 & 92.50 \\
Protein $^{(1)}$ & 1.85 & 1.43 & 0.84 & 22.86 & 25.11 & 0.36 \\
Lipid $^{(1)}$ & 0.20 & 1.56 & 0.20 & 1.46 & 0.88 & 0.33 \\
Total carbohydrates $^{(2)}$ & 3.35 & 7.99 & 14.90 & 63.95 & 61.01 & 0.25 & 48.99 \\
Ash $^{(1)}$ & 1.00 & 1.00 & 0.50 & 4.30 & 4.60 & 3.00 \\
\hline
\end{tabular}

${ }^{(1)}$ Standard deviation less than $2 \%$.

${ }^{(2)}$ Total carbohydrates content of food/beverages was calculated by difference, rather than analysed directly.

TABle 2: Sucrose, glucose, and fructose content of the selected food/beverages ( $\mathrm{g} / 100 \mathrm{~g}$ edible material).

\begin{tabular}{lccccccc}
\hline Edible material & Red chicory & Mushroom & Raspberry & Green tea & Black tea & Cranberry & Beer \\
\hline Glucose $^{(1)}$ & 0.86 & 0.12 & 0.63 & 0.54 & trace & 3.07 & trace \\
Fructose $^{(1)}$ & 0.70 & trace & 0.71 & trace & 0.00 & 0.78 & trace \\
Sucrose $^{(1)}$ & trace & 0.02 & 0.24 & 0.94 & 0.00 & 0.21 & trace \\
\hline
\end{tabular}

${ }^{(1)}$ Standard deviation less than $3 \%$.

TABLE 3: Monomeric and dimeric sugars presence in the selected food/beverages.

\begin{tabular}{|c|c|c|c|c|c|c|c|}
\hline & Red chicory & Mushroom & Raspberry & Green tea & Black tea & Cranberry & Beer \\
\hline Mannose & $\mathrm{X}$ & - & X & $\mathrm{X}$ & $\mathrm{X}$ & $\mathrm{X}$ & - \\
\hline Rhamnose & - & - & - & $\mathrm{X}$ & - & $\mathrm{X}$ & - \\
\hline Xilose & - & - & $\mathrm{X}$ & - & - & - & - \\
\hline Maltose & $\mathrm{X}$ & - & - & $\mathrm{X}$ & - & - & $\mathrm{X}$ \\
\hline
\end{tabular}

X: present.

—: absent.

TABLE 4: Microbial contamination of selected food/beverages.

\begin{tabular}{|c|c|c|c|c|c|c|}
\hline Food/beverage & $\begin{array}{c}\text { Mesophilic } \\
\text { bacteria } \\
(\mathrm{cfu} / \mathrm{mL}) \\
\end{array}$ & $\begin{array}{c}\text { Psychrophilic } \\
\text { bacteria } \\
(\mathrm{cfu} / \mathrm{mL}) \\
\end{array}$ & $\begin{array}{l}\text { Moulds } \\
(\mathrm{cfu} / \mathrm{mL})\end{array}$ & $\begin{array}{c}\text { Enteric indicator } \\
\text { Bacteria } \\
(\mathrm{cfu} / \mathrm{mL}) \\
\end{array}$ & $\begin{array}{l}\text { Environmental } \\
\text { indicator bacteria } \\
(\mathrm{cfu} / \mathrm{mL})\end{array}$ & $\begin{array}{c}\text { Other microbial } \\
\text { indicators } \\
(\mathrm{cfu} / \mathrm{mL})\end{array}$ \\
\hline Red chicory & 2500 & 3560 & 1400 & 740 & 1000 & $<1$ \\
\hline Mushroom & 4 & 8 & 2 & $<1$ & $<1$ & $<1$ \\
\hline Raspberry & 400 & 570 & 160 & $<1$ & $<1$ & $<1$ \\
\hline Green tea & 2 & 20 & 10 & $<1$ & $<1$ & $<1$ \\
\hline Black tea & 4 & 600 & 52 & $<1$ & $<1$ & $<1$ \\
\hline Cranberry & $<1$ & $<1$ & $<1$ & $<1$ & $<1$ & $<1$ \\
\hline Beer & 1 & 3 & $<1$ & $<1$ & $<1$ & $<1$ \\
\hline
\end{tabular}

TABLE 5: Food/beverage mineral contents, expressed in ppm.

\begin{tabular}{lccccccccccc}
\hline Food & $\mathrm{F}$ & $\mathrm{Zn}$ & $\mathrm{Sr}$ & $\mathrm{Mo}$ & $\mathrm{B}$ & $\mathrm{Li}$ & $\mathrm{Se}$ & $\mathrm{Be}$ & $\mathrm{Cu}$ & $\mathrm{Pb}$ \\
\hline Red chicory & 0.030 & 1.040 & 0.020 & $<0.003$ & 0.080 & $<0.003$ & $<0.001$ & $<0.003$ & 0.020 & $<0.003$ \\
Mushroom & 0.010 & 1.030 & 0.150 & $<0.003$ & 0.380 & $<0.003$ & $<0.002$ & 0.003 & 0.170 & $<0.003$ \\
Raspberry & $<0.020$ & 0.760 & 0.150 & $<0.002$ & 0.025 & $<0.002$ & $<0.001$ & $<0.002$ & 0.120 & $<0.002$ \\
Green tea & 42.000 & 9.500 & 3.400 & $<0.100$ & 4.200 & $<0.100$ & $<0.060$ & $<0.100$ & 2.600 & $<0.100$ \\
Black tea & 44.000 & 8.800 & 1.200 & $<0.100$ & 2.640 & $<0.100$ & $<0.060$ & $<0.100$ & 0.880 & $<0.100$ \\
Cranberry & $<0.500$ & 0.060 & 0.020 & $<0.010$ & 0.050 & $<0.010$ & $<0.003$ & $<0.005$ & 0.023 & $<0.005$ \\
Beer & 0.160 & 0.040 & 0.060 & $<0.010$ & 0.030 & $<0.010$ & $<0.006$ & $<0.005$ & $<0.005$ & $<0.005$ \\
\hline
\end{tabular}


TABLE 6: Amount of raw food needed to obtain $100 \mathrm{~mL}$ of extracts, the extract $\mathrm{pH}$ values, sugars, and total polyphenols content of the extracts.

\begin{tabular}{|c|c|c|c|c|c|c|}
\hline Extract & $\begin{array}{c}\text { g raw } \\
\text { material } / 100 \mathrm{~mL} \\
\text { extract }\end{array}$ & $\mathrm{pH}$ value & Sucrose $^{(1)}$ & $\begin{array}{l}\text { Glucose }^{(1)} \\
\mathrm{g} / 100 \mathrm{~mL}\end{array}$ & Fructose $^{(1)}$ & $\begin{array}{c}\text { Total polyphenol } \\
\text { content } \\
(\mathrm{mg} / 100 \mathrm{~mL})\end{array}$ \\
\hline Red chicory & $177 \pm 2.10$ & $6.05 \pm 0.04$ & Trace & 1.52 & 1.22 & $75.00 \pm 4.16$ \\
\hline Mushroom & $140 \pm 1.60$ & $5.79 \pm 0.05$ & 0.03 & 0.18 & trace & $53.00 \pm 2.27$ \\
\hline Raspberry & $224 \pm 2.40$ & $3.21 \pm 0.02$ & 0.55 & 1.40 & 1.58 & $107.00 \pm 7.48$ \\
\hline Green tea & $5.00 \pm 0.02$ & $4.05 \pm 0.02$ & 0.05 & 0.03 & Trace & $289.00 \pm 9.08$ \\
\hline Black tea & $5.00 \pm 0.02$ & $4.53 \pm 0.02$ & 0.00 & Trace & 0.00 & $272.00 \pm 6.69$ \\
\hline Cranberry & & $2.90 \pm 0.01$ & 0.22 & 3.07 & 0.78 & $207.00 \pm 7.00$ \\
\hline Beer & & $3.48 \pm 0.02$ & Trace & Trace & Trace & $153.00 \pm 6.40$ \\
\hline
\end{tabular}

${ }^{(1)}$ Standard deviation less than $3 \%$.

remineralisation and inhibits oral pathogen proliferation so helping in preventing caries lesion. It is well known that rich in F tooth-paste daily used acts consistently reducing caries incidence.

Also as regards zinc $(\mathrm{Zn})$ and strontium $(\mathrm{Sr})$, a positive effect is considered to be clearly demonstrated. Zn cations, as other heavy metal cations, possess antimicrobial activity and, due to this, $\mathrm{Zn}$ is commonly added in the products prepared for oral care, such as tooth-pastes and mouthwashes.

Because of its chemical similarity to calcium $(\mathrm{Ca}), \mathrm{Sr}$ can replace $\mathrm{Ca}$ in HA crystals of teeth and bone imparting additional strength to these tissues. It was found that when rats are fed increased amounts of Sr, their teeth became thicker and stronger. In a 10-year study, carried out by the United States Navy Dental Service, a very low incidence of caries was registered among naval recruits coming from a small area around Rossburg, Ohio, where the water contains unusually high concentrations of Sr [32]. Again, epidemiologic studies have shown that $\mathrm{Sr}$ concentrations of 6 to $10 \mathrm{mg} / \mathrm{L}$ in the water supply are associated with a reduced incidence of cavities. The results of the epidemiologic investigations were confirmed by administering these levels of strontium in experimental animal studies [33].

Other trace elements in food and water have now been linked with dental caries [34]. Boron (B), vanadium (Va), and, above all, molybdenum (Mo) have been associated with reduced caries prevalence, whereas selenium (Se) and lead $\mathrm{Pb})$ appear to have adverse effects.

To be submitted to the biological screening tests, the raw selected materials required the sample preparation.

Whereas dark beer needed simply dealcoholation with restoring the volume and cranberry the dilution of the concentrated juice, the solid foods required the preparation of solutions useful for the biological assays. In this case, the water soluble components were obtained by homogenisation, centrifugation, and filtration of the raw materials as regards red chicory, mushroom, and raspberry; conversely, considering green and black tea, the leaves were treated as commonly done to prepare the infusion used as a beverage as described in Materials and Methods. In general, the solutions prepared to be submitted to the biological assays will be defined as extracts. In Table 6 , the amounts of raw food need- ed to obtain $100 \mathrm{~mL}$ of extracts, extract $\mathrm{pH}$ values, content of sugars, and total polyphenols are reported.

The extracts were submitted to the same analysis as the raw foods/beverages and to sterile ultrafiltration that microbiological quality control showed to be efficient.

With respect to the raw materials, the extracts do not contain, but in traces, proteins and lipids, and, considering carbohydrates, they contain just the water soluble sugars. With regards raspberry, red chicory, and mushroom, as expected, glucose, fructose, and sucrose resulted to occur in a slightly higher concentration than in the whole raw materials. This is due to the fact that the determination of sugars as well as mineral ions requires the separation of these soluble analytes from the insoluble constituents of the food matrices. The separation had to be carried out in the same way used to obtain the extracts in which the water soluble components are actually determined. On the contrary, when the extraction of such water soluble analytes is carried out by infusion in a large volume of water, the extracts obtained present a very lower concentration of such components in comparison with the raw materials, and this is the case of tea leaves. So it is apparent that the analyte concentrations reported for the raw materials are often the results of calculations carried out on the basis of the analyte amounts actually determined in the extracts (Figure 1).

In general, this investigation shows that, among the selected food/beverages, tea beverages are good sources of $\mathrm{F}$, $\mathrm{Zn}, \mathrm{Sr}, \mathrm{B}$, copper $(\mathrm{Cu})$, and polyphenols. Raspberry can supply us with relevant amounts of $\mathrm{Zn}, \mathrm{Sr}, \mathrm{B}$, and $\mathrm{Cu}$, whereas red chicory contains good concentrations of B. Mushroom is very rich in F, Zn, Sr, B, and $\mathrm{Cu}$. Beer is rich in F, Zn, and Se. All the selected food/beverages are rich in total polyphenols, with green and black tea beverages, cranberry juice, and beer containing the highest concentration of such components. The extracts obtained from each food/beverages were submitted to microbiological assays to determine their activity against oral pathogens and their virulence factors. The results of such tests indicated the best potential against infectious oral diseases for mushroom, red chicory, and raspberry [35, 36].

To obtain preliminary indications about the molecular mass of the compounds responsible for the detected 


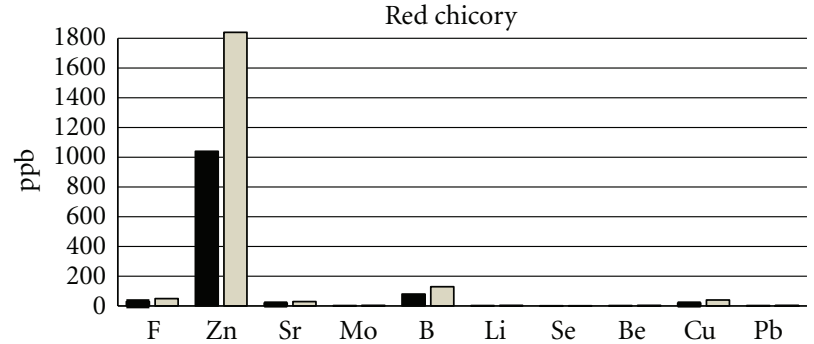

(a)

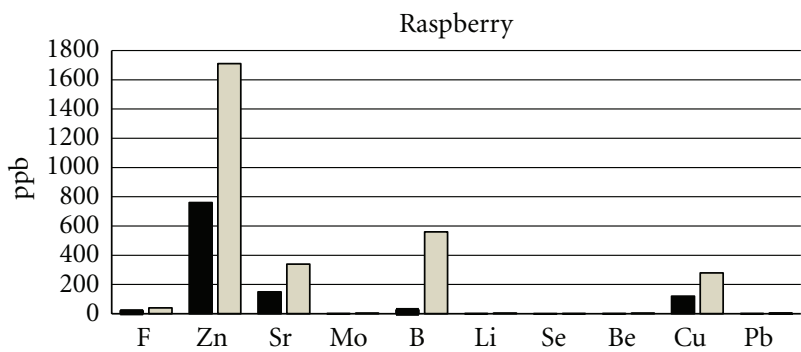

(c)

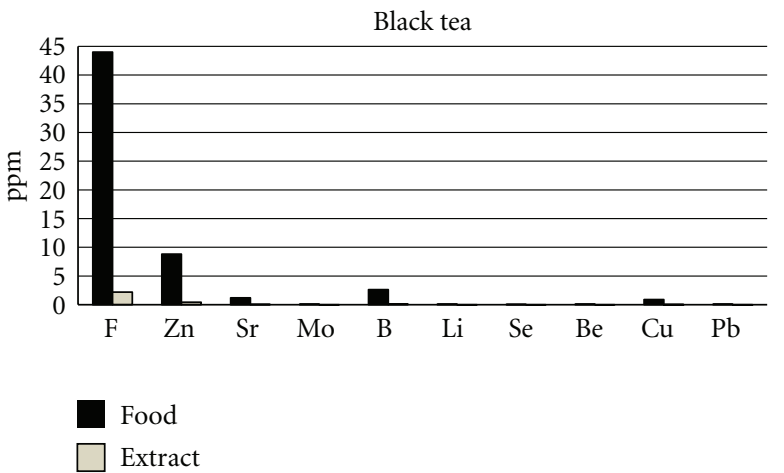

(e)

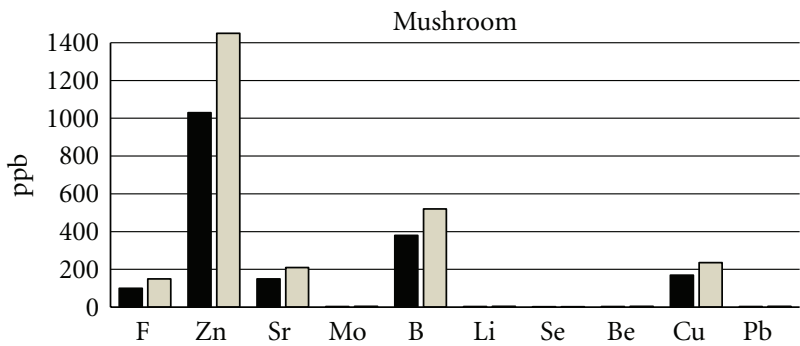

(b)

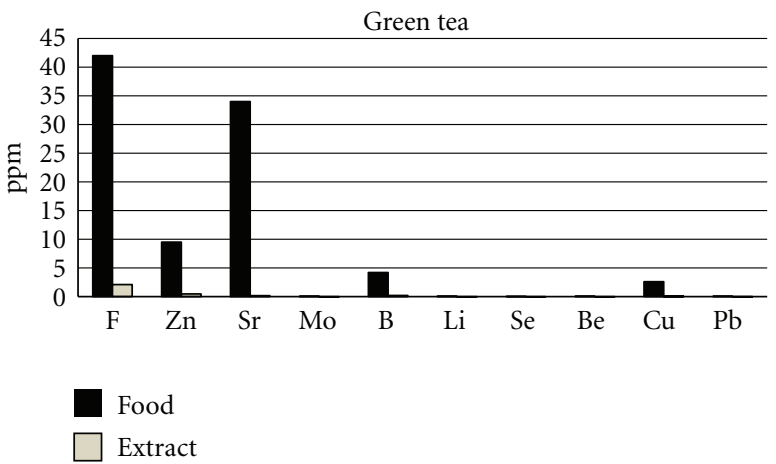

(d)

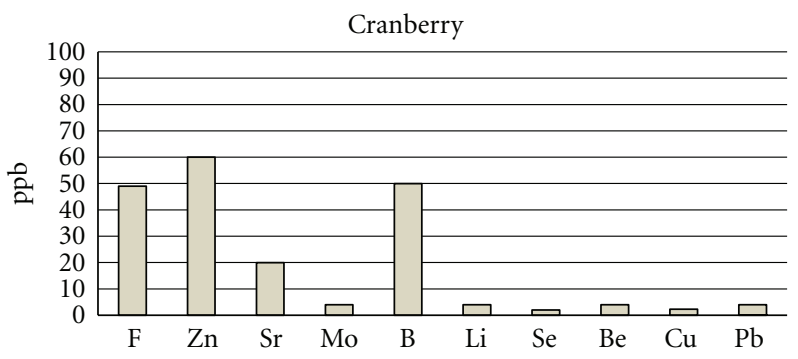

(f)

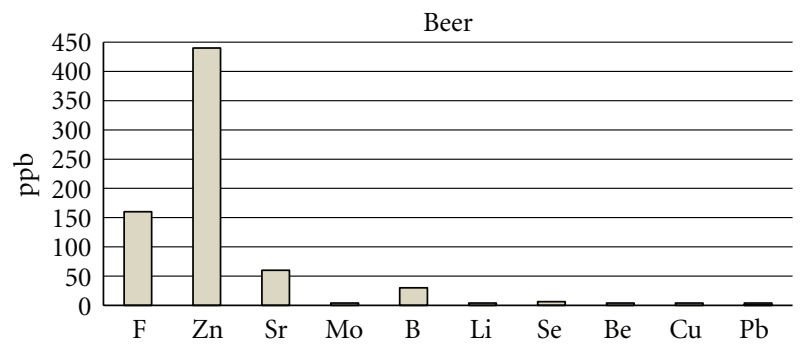

(g)

FIGURE 1: Mineral content of food/beverages and their extracts (espressed in ppm or ppb).

activities, raspberry extract was fractionated by dialysis due to its high viscosity and density, differently from chicory and mushroom extracts that were fractionated by ultradiafiltration. The dialysis procedure was carried out using dialysis membrane with a $3,500 \mathrm{Da}$ cutoff, which allowed the separation of LMM components (mono- and disaccharides, organic acids, flavonoids and condensed and hydrolysable tannins with low degree of polymerization, and ion ele- ments) from polymeric components, such as high degree of polymerization tannins, complex carbohydrates, and proteins. Due to the very acidic $\mathrm{pH}$ values of dialysis fractions (LMM fraction $\mathrm{pH}=2.71 \pm 0.12$ and HMM fraction $\mathrm{pH}=$ $3.20 \pm 0.01$ ), which could interfere with subsequent microbiological assays, the $\mathrm{pH}$ value of both fractions was brought to $\mathrm{pH}$ 4.50. Then, dialysis fractions were sterilized using ultrafiltration and freeze-dried. 
With regards to red chicory and mushroom, the extract fractionation into LMM and HMM fractions was performed using a 5,000 MWCO PES membrane. This procedure resulted in the loss of 50\% and 33\% diafiltrate components for red chicory and mushroom, respectively, which remained in the retentate; so the lost of such components had to be restored to obtain a diafiltrate fraction with the LMM components at the same concentration as in the raw extract. Conversely, the retentate had to be further treated to eliminate the residue LMM components. The right concentration of the LMM components for chicory in the diafiltrates was achieved submitting to diafiltration procedure a double volume of extract and a volume of extract added of 33\% for mushroom. The retentate purification was performed submitting HMM fraction to dialysis process. Diafiltrate and retentate solutions (mushroom: $\mathrm{LMM}$ pH $=6.15 \pm 0.11, \mathrm{HMM}$ pH $=6.80 \pm$ 0.13 ; red chicory: $\mathrm{LMM} \mathrm{pH}=5.90 \pm 0.09, \mathrm{HMM}$ pH $=6.55 \pm$ 0.10 ) were sterilized using ultrafiltration $0.20 \mu \mathrm{m}$ membrane and freeze-dried, and stored for microbiological assays.

\section{Conclusions}

In conclusion, the present investigation allows to know the macronutrient, mineral ions, and polyphenol content of seven food/beverages grown in defined area but exported to various countries around the world. While the macronutrient composition of such food/beverages is generally well known and tabulated as mean values, for most of these materials, very scarce literature data about their content in mineral micronutrient are available. Tea leaves resulted to be the raw materials richest in all the elements detected as mineral ions, anyway tea beverages resulted to be the richest just in fluoride ion among the selected food/beverages. The highest content in zinc ion was found in red chicory, raspberry, and mushroom. Raspberry is the richest food in strontium and boron, beer in selenium, and raspberry and mushroom in copper. As regards polyphenols, beer, cranberry juice, and, above all, green and black tea are very rich in these components confirming these beverages to be important sources of such healthy components. Among the selected food/beverage extracts, raspberry, red chicory, and mushroom extracts, considering, in the whole, the results of microbiological assays, showed the highest potential action against oral pathogens. The fractionation of the water soluble components occurring in these extracts, carried out on the basis of their molecular mass, showed that both the HMM and LMM obtained fractions of each food, present any activity in the microbiological tests indicating that more active compounds occur in these foods with the LMM fractions containing the components presenting the highest potential action against the oral pathogens.

\section{Abbreviations}

HA: Hydroxyapatite

ICP-MS: Inductively coupled plasma-mass spectrometer

LOD: Limit of detection

LOQ: Limit of quantification

MMCO: Molecular mass cutoff
LMM: Low molecular mass

HMM: High molecular mass.

\section{Acknowledgment}

The research leading to these results has received funding from the European Union's Sixth Framework Programme (FP6) under the contract FOOD-CT-2006-036210 (project NUTRIDENT).

\section{References}

[1] "Regulation (EC) No 1924/2006 of the European Parliament and of the Council of 20 December 2006 on nutrition and health claims made on foods," Official Journal of the European Union, vol. 12, Article ID L 12/4, 2007.

[2] "Directive 2002/46/EC of the European Parliament and of the Council of 10 June 2002 on the approximation of the laws of the Member States relating to food supplements," Official Journal of the European Communities, vol. 45, Article ID L 183/52, 2002.

[3] A. C. Brown and C. M. Hasler, "Position of the American Dietetic Association: functional foods," Journal of the American Dietetic Association, vol. 109, no. 4, pp. 735-746, 2009.

[4] T. Ooshima, T. Minami, W. Aono et al., "Oolong tea polyphenols inhibit experimental dental caries in SPF rats infected with S. mutans," Caries Research, vol. 27, no. 2, pp. 124-129, 1993.

[5] T. Ooshima, T. Minami, M. Matsumoto, T. Fujiwara, S. Sobue, and S. Hamada, "Comparison of the cariostatic effects between regimens to administer oolong tea polyphenols in SPF rats," Caries Research, vol. 32, no. 1, pp. 75-80, 1998.

[6] T. Ooshima, T. Minami, W. Aono, Y. Tamura, and S. Hamada, "Reduction of dental plaque deposition in humans by oolong tea extract," Caries Research, vol. 28, no. 3, pp. 146-149, 1994.

[7] J. M. T. Hamilton-Miller, "Anti-cariogenic properties of tea (Camellia sinensis)," Journal of Medical Microbiology, vol. 50, no. 4, pp. 299-302, 2001.

[8] S. Otake, M. Makimura, T. Kuroki, Y. Nishihara, and M. Hirasawa, "Anticaries effects of polyphenolic compounds from Japanese green tea," Caries Research, vol. 25, no. 6, pp. 438-443, 1991.

[9] M. Daglia, M. T. Cuzzoni, and C. Dacarro, "Antibacterial activity of coffee," Journal of Agricultural and Food Chemistry, vol. 42, no. 10, pp. 2270-2272, 1994.

[10] M. Daglia, M. T. Cuzzoni, and C. Dacarro, "Antibacterial activity of coffee: relationship between biological activity and chemical markers," Journal of Agricultural and Food Chemistry, vol. 42, no. 10, pp. 2273-2277, 1994.

[11] M. Daglia, R. Tarsi, A. Papetti et al., "Antiadhesive effect of green and roasted coffee on S. mutans' adhesive properties on saliva coated hydroxyapatite beads," Journal of Agricultural and Food Chemistry, vol. 50, no. 5, pp. 1225-1229, 2002.

[12] M. Daglia, A. Papetti, P. Grisoli et al., "Isolation, identification, and quantification of roasted coffee antibacterial compounds," Journal of Agricultural and Food Chemistry, vol. 55, no. 25, pp. 10208-10213, 2007.

[13] M. Daglia, A. Papetti, P. Grisoli, C. Aceti, C. Dacarro, and G. Gazzani, "Antibacterial activity of red and white wine against oral streptococci," Journal of Agricultural and Food Chemistry, vol. 55, no. 13, pp. 5038-5042, 2007.

[14] M. Daglia, M. Stauder, A. Papetti et al., "Isolation of red wine components with anti-adhesion and anti-biofilm activity 
against Streptococcus mutans," Food Chemistry, vol. 119, no. 3, pp. 1182-1188, 2010.

[15] A. Papetti, C. Pruzzo, M. Daglia et al., "Effect of barley coffee on the adhesive properties of oral streptococci," Journal of Agricultural and Food Chemistry, vol. 55, no. 2, pp. 278-284, 2007.

[16] M. Stauder, A. Papetti, M. Daglia et al., "Inhibitory activity by barley coffee components towards Streptococcus mutans biofilm," Current Microbiology, vol. 61, no. 5, pp. 417-421, 2010.

[17] T. Ooshima, Y. Osaka, H. Sasaki, K. Osawa, H. Yasuda, and M. Matsumoto, "Cariostatic activity of cacao mass extract," Archives of Oral Biology, vol. 45, no. 9, pp. 805-808, 2000.

[18] K. Osawa, K. Miyazaki, S. Shimura, J. Okuda, M. Matsumoto, and T. Ooshima, "Identification of cariostatic substances in the cacao bean husk: their anti-GTF and antibacterial activities," Journal of Dental Research, vol. 80, no. 11, pp. 2000 2004, 2001.

[19] K. Ito, Y. Nakamura, T. Tokunaga, D. Iijima, and K. Fukushima, "Anti-cariogenic properties of a water-soluble extract from cacao," Bioscience, Biotechnology and Biochemistry, vol. 67, no. 12, pp. 2567-2573, 2003.

[20] G. F. Ferrazzano, I. Amato, A. Ingenito, A. De Natale, and A. Pollio, "Anti-cariogenic effects of polyphenols from plant stimulant beverages (cocoa, coffee, tea)," Fitoterapia, vol. 80, no. 5, pp. 255-262, 2009.

[21] S. Duarte, P. L. Rosalen, M. F. Hayacibara et al., "The influence of a novel propolis on mutans streptococci biofilms and caries development in rats," Archives of Oral Biology, vol. 51, no. 1, pp. 15-22, 2006.

[22] S. A. Libério, A. L. A. Pereira, M. J. A. M. Araújo et al., "The potential use of propolis as a cariostatic agent and its actions on mutans group streptococci," Journal of Ethnopharmacology, vol. 125, no. 1, pp. 1-9, 2009.

[23] P. Cunniff, Ed., Official Method of Analysis of AOAC International, 920.49-N. 27.1.01, 1995.

[24] P. Cunniff, Ed., Official Method of Analysis of AOAC International, 925.19-N30.1.32, 1995.

[25] P. Cunniff, Ed., Official Method of Analysis of AOAC International, 920.53-N. 27.1.26, 1995.

[26] P. Cunniff, Ed., Official Method of Analysis of AOAC International, 920.103-N. 30.1.33, 1995.

[27] P. Cunniff, Ed., Official Method of Analysis of AOAC International, 925.18-N. 30.1.30, 1995.

[28] M. Q.-K. Talukder, "A rapid quantitative thin layer chromatographic separation of fucose from other neutral mosacchaires: an application to separate other sugars of physiological interest," Journal of Chromatography A, vol. 57, no. C, pp. 391395, 1971.

[29] M. Daglia, A. Papetti, C. Aceti, B. Sordelli, C. Gregotti, and G. Gazzani, "Isolation of high molecular weight components and contribution to the protective activity of coffee against lipid peroxidation in a rat liver microsome system," Journal of Agricultural and Food Chemistry, vol. 56, no. 24, pp. 1165311660, 2008.

[30] Micro-Organisms in Foods 1 'Their Significance and Methods of Enumeration', University of Toronto Press International Commission on Microbiological Specifications for Foods (ICMSF) of the International Association of Microbiological Societies, Toronto, Canada, 2nd edition, 1988.

[31] Micro-Organisms in Foods 2 'Sampling for Microbiological Analysis: Principles and Specific Applications', University of Toronto Press International Commission on Microbiological
Specifications for Foods (ICMSF) of the International Association of Microbiological Societies, Toronto, Canada, 2nd edition, 1986.

[32] R. J. Herbison and S. L. Handelman, "Effect of trace elements on dissolution of hydroxyapatite by cariogenic Streptococci," Journal of Dental Research, vol. 54, no. 6, pp. 1107-1114, 1975.

[33] Y. Henrotin, A. Labasse, S. X. Zheng et al., "Strontium ranelate increases cartilage matrix formation," Journal of Bone and Mineral Research, vol. 16, no. 2, pp. 299-308, 2001.

[34] B. E. Davies and R. J. Anderson, "The epidemiology of dental caries in relation to environmental trace elements," Cellular and Molecular Life Sciences, vol. 43, pp. 87-92, 1987.

[35] D. Spratt, D. Spratt, M. Stauder et al., "Evaluation of plant and fungal extracts for their potential anti-gingivitis and anticaries activity," Journal of Biomedicine and Biotechnology. In press.

[36] L. Ciric, A. Tymon, E. Zaura et al., "In vitro assessment of shiitake mushroom (Lentinula edodes) extract for its antigingivitis activity," Journal of Biomedicine and Biotechnology. In press. 

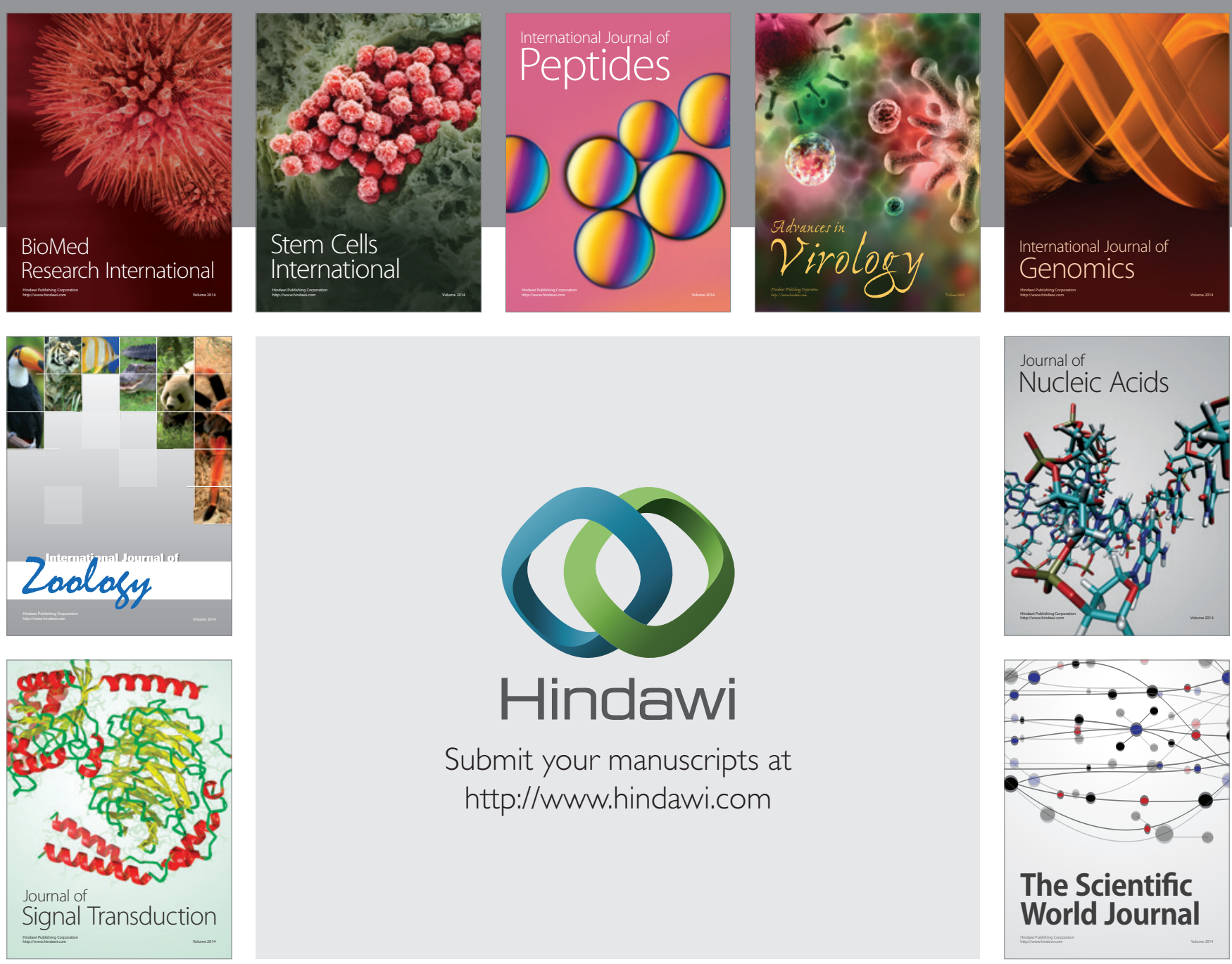

Submit your manuscripts at

http://www.hindawi.com
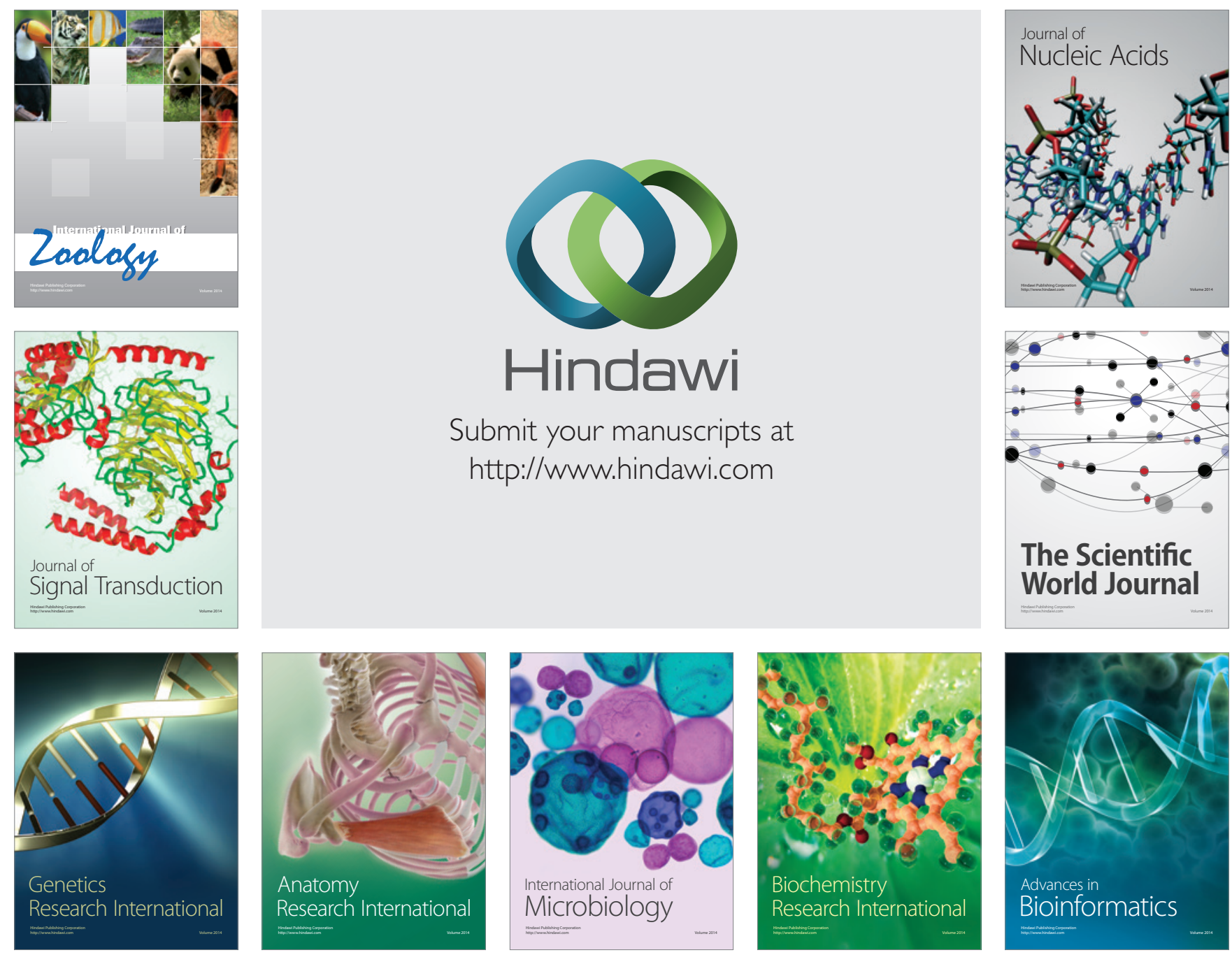

The Scientific World Journal
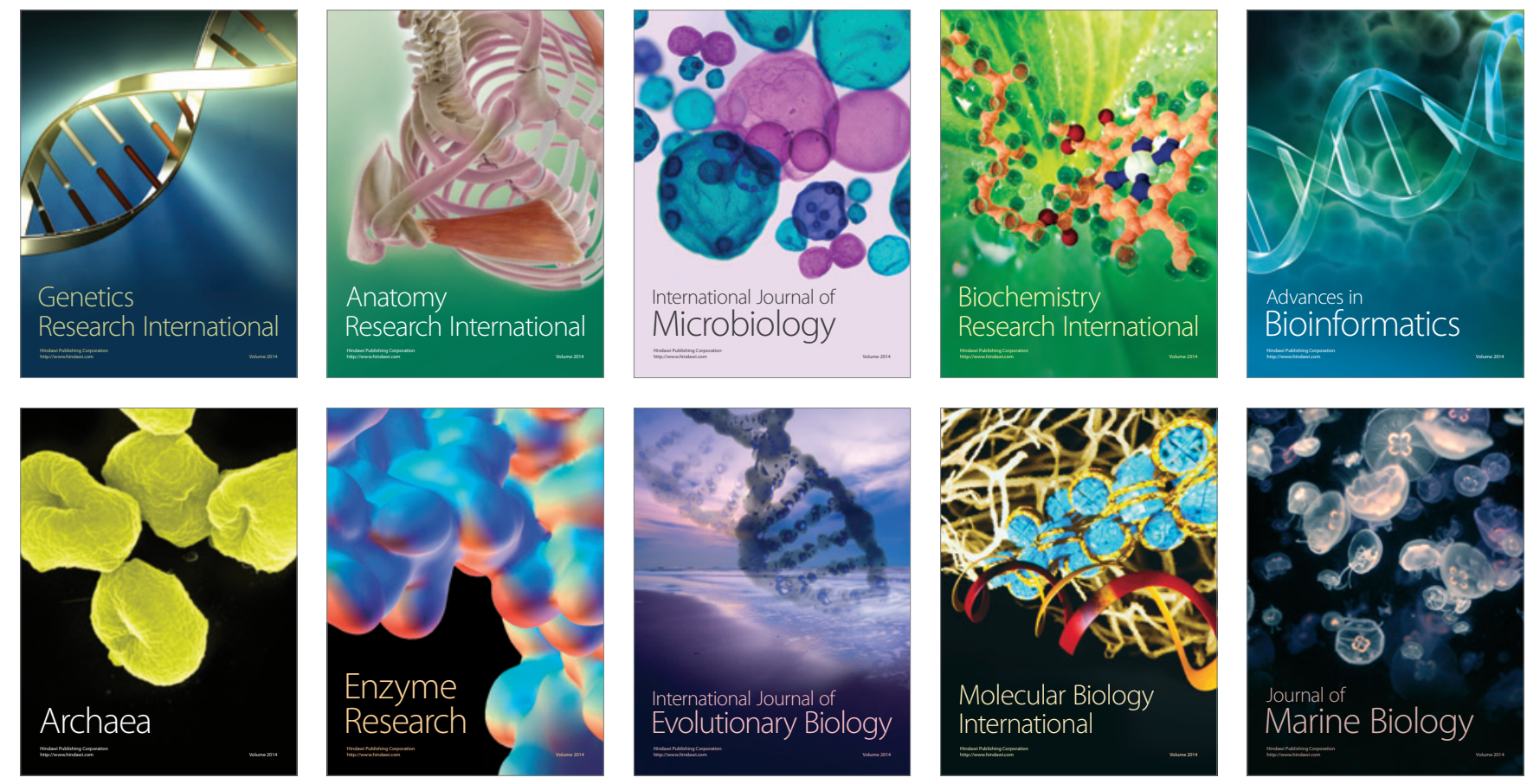